\title{
Students' Experience with Online Simulation Games: From Computer Anxiety to Satisfaction
}

\author{
José M. Pina And Victoria Bordonaba-Juste* \\ Department of Management, Faculty of Economics and Business Administration, University of \\ Zaragoza, Gran Vía 2, 50.005 Zaragoza, Spain \\ ${ }^{*}$ Corresponding author: vbordon@unizar.es
}

\begin{abstract}
It is currently of great importance to analyse the experience of the application of new technologies in teaching. This research paper examines the personality traits of students and their environment, which may influence the experience of college students using online simulation games. Previous literature suggests that individuals may feel anxiety when using the computer, which may vary according to their perception of being able to control the situation, their perceived importance of the activities and any prior knowledge that they have. Therefore, the first objective of this research is to analyse the relationship between computer anxiety, locus of control and perceived importance of the computer activities. The second objective is to examine whether this relationship is moderated by knowledge. The third objective is to identify user clusters to examine which factors are most important to explain user satisfaction with online simulation games. Results showed that students experience greater computer anxiety when the situation is perceived as important and the locus of control is high, being these effects moderated by their previous knowledge. Moreover, a cluster analysis threw light on the existence of cluster of users whose satisfaction mainly depends on their game score. These results have implications for both academic and research purposes.
\end{abstract}

\section{RESEARCH HIGHLIGHTS}

- We examine the drivers of computer anxiety.

- Computer anxiety is related with personal traits and individual's knowledge.

- We examine a real experience of using online simulation games in education.

Keywords: computer anxiety; online simulation games; locus of control; satisfaction; cluster analysis

Editorial Board Member: Dr Ruven Brooks

Received 10 May 2017; Revised 3 November 2017; Editorial Decision 25 January 2018; Accepted 31 January 2018

\section{INTRODUCTION}

Business simulation games are a new type of software that can emulate aspects of the business world, such as leadership and teamwork under time constraints, decision making in competitive situations and knowledge of the consequences of related decisions (Siewiorek et al., 2012; Voss and Brennan, 2010; Walters and Coalter, 1997). The goal of business simulation games is to provide students with an experience applicable to the real world by giving them the means to act as if they were leading their own company (Martin, 2000). However, while these games are useful for obtaining business skills, as we will see below, some of their effects are still unknown.

The application of new information and communication technologies (ICTs) in education has opened the debate about their effect on students' experience. In this paper, students' experience is assessed through two main dependent variables, computer anxiety and satisfaction, and a number of explanatory factors including locus of control, perceived importance and knowledge as the main ones. To our knowledge, there are no published studies that evaluated the interactions between these variables in a game setting. 
In particular, the use of online simulation games gives students a positive experience and satisfaction (Tao et al. 2012). Student satisfaction with the use of simulation games is enhanced when students believe they are the protagonist of positive results achieved, or at least more so than other external causes. This is what is known as 'internal locus of control', which can help generate positive emotions and satisfaction among students (Amyx et al., 2000). This sense of power is also likely to foster both creativity and innovative spirit (Burroughs and Mick, 2004), especially when individuals are under time constraints (Cools and van den Broeck, 2008), which are often applied in online simulation games.

While learning methods via ICTs is extremely useful and interesting in education, it also has effects that often go unnoticed by teachers, such as increased levels of anxiety experienced by students. In the literature, the term 'computer anxiety' has emerged as a psychological construct that is defined as fear of or aversion to using computers, which manifest as beliefs and negative emotions (Bozionelos, 2001). For college students, who can be considered digital natives, the challenge is not for them to learn to use the mouse or Windows, but in learning new tools or software, such as SPSS (Hsu et al., 2009). In this sense, Huang et al. (2013) observed that Web 2.0 apps, which are collaborative in nature (such as blogs, wikis and online games) tend to generate anxiety when they are used as teaching tools. In a teaching environment, computer anxiety negatively affects satisfaction (Liaw and Huang, 2013; Sun et al., 2008), thereby reducing the perceived usefulness of the technology and its ease of use, which can reduce its implementation or continued use in the future (Hsu et al., 2009; Mac Callum et al., 2014). In online business simulation games, there are relevant user features, such as previous knowledge or motivation, that are difficult to control and evaluate (Größler, 2004). The user's experience with the computer itself provides knowledge that helps reduce anxiety, especially for users with higher initial levels of anxiety (Bozionelos, 2001). This situation may also depend on the user's perception of the online activities' importance (Kim and Davis, 2009). In addition, students who feel that the consequences of their decisions are due more to their own behaviors and attitudes than to the environment around them perceive a higher internal, than external, locus of control. Therefore, in an online environment, users that are characterized by an external locus of control often feel that they have more intention to use the technology for the positive feelings generated by this type of locus (Koo, 2009). Despite the importance of analysing these issues in the use of technology in the teaching field, to our knowledge, no previous research has analysed these computers anxiety factors in students, and the relation between the factors and student satisfaction for active learning purposes.

In summary, this study has three objectives related to the use of online simulation games as a method of learning and assessment (1) to analyse whether computer anxiety increases with the internal locus of control, and the perception of the perceived importance; (2) examine whether the students' knowledge mitigates the effects of these two determinants of computer anxiety; and (3) perform a student cluster analysis regarding satisfaction and experience with the use of online simulation games.

To achieve the objectives framed within the context of business simulation games, we developed an empirical study of an experimental nature. The next sections will explain the hypotheses, the methodology and the results obtained in this study. Finally, this paper will conclude with an analysis of the findings and academic implications.

\section{LITERATURE REVIEW}

\subsection{Computer anxiety}

Computer anxiety and its relation to factors concerning the user's personality and the environment are rooted in self-efficacy theory. According to this theory, the behavior of individuals is determined by the beliefs they have about their abilities, rather than their actual capabilities (Parayitam et al., 2010). Thus, individuals have self-efficacy with computers when they feel confident with its use. Conversely, the lack of self-efficacy generates computer anxiety (Osatuyi, 2015).

Computer anxiety is an emotional response to fear arising from using the computer. It is closely related to the risk and uncertainty that is inherent in the use of digital products and online services, so it becomes an important factor when adopting or continuing to use a technology (Barbeite and Weiss, 2004; Beckers et al., 2007; Parayitam et al., 2010; Rahimi and Yadollahi, 2011; Saadé and Kira, 2007; Smith and Caputi, 2007). Negative effects thereof include damage to the device and distress at seeming 'stupid' for not knowing how to use the technology correctly (Mac Callum et al., 2014). In addition to these negative consequences, in some online environments, users risk exposing their private information, which will lead to a decrease in their intention to continue using the technology in future. In fact, there is a concern that other users or the company that manages the technology can access all of the user's data, even if it is private (Osatuyi, 2015).

Based on previous literature, the key factors that can influence students' computer anxiety and their experience of using simulation games online are discussed below.

\subsection{Locus of control}

A key factor that may influence individuals' computer anxiety levels is the locus of control. This factor is a personality aspect, which has been extensively studied in psychology, wherein individuals have certain beliefs about the causes of 'rewards' and 'punishments', and have the feeling that their life is (or is not, depending on whether the locus is internal or external) under their control (Rotter, 1966). Just as with computer anxiety, this paper will not consider the locus of control as a permanent state of the individual, but rather a transitional one, as it can be 
stimulated by environmental conditions. In this sense, Patrick and Hagtvedt (2012) used the term 'psychological training' to refer to perceived control in specific situations. For example, Cleveland et al. (2005) conceptualized the 'locus of environmental control' as the degree to which people believe they have the potential to cause environmental effects through their own actions. Other authors have also focused on the concept of 'locus of health control' (Amyx et al., 2000; Wallston et al., 1978).

According to attribution theory, people tend to assign causes to events in which they are participants, which ultimately guide their behavior (Heider, 1958). In general, individuals may think that they are the 'masters of their own destiny', and feel responsible for the results they have obtained, whether positive or negative; alternatively, they may feel that these results depend mainly on external factors (fortune, external circumstances or situations, and so forth). The former case entails an 'internal locus', while the latter refers to an 'external locus' of control (Rotter, 1966).

There is no consensus in the literature regarding which kind of locus has a greater effect on computer anxiety. On the one hand, in online environments, individuals with a higher external than internal locus have more trouble managing distractions and other stimuli when working at the computer, so they experience greater stress (Hair et al., 2007). This idea is supported by the fact that these individuals that have a heightened sense of time and control (Joo et al., 2011). However, for individuals with a higher external locus of control, their feeling of pleasure is reinforced by being in the world that is recreated by the online game, and they benefit from the experience and the social affiliation that arises from the game's use; thus, they have a greater intention to play compared with those who have a higher internal locus of control (Koo, 2009). As this research aims to analyse student anxiety in the use of online simulation games (through computer use and activities related to it), it is proposed that:

H1: When playing online simulation games, students experience greater computer anxiety when they perceive a higher internal locus of control, compared to those that have a higher external locus of control.

\subsection{Perceived importance}

It is safe to assume that computer anxiety will increase as the importance of the situation or scenario in which the individual is placed increases. In the teaching field, Vitasari et al. (2010) asked 770 college students which educational factors led them to stress, finding that their main source of anxiety was exams, followed by class presentations, language and social relations. However, this situation is not only applicable to a purely academic context; in other situations of high stress and high importance, such as the case of medical problems, anxiety may also be triggered (Boker et al., 2002).

In an online context, it has been shown that the greater the importance that individuals assign to an activity, the more problems they will have with the use of computers (Kim and Davis, 2009). Although the use of a business simulation game as a teaching tool is a sufficient motivational element, we expect that the perceived importance of the activity can lead to some students to feel more computer anxiety than others. Business simulation games entail a type of experiential learning, in which students learn by 'doing' and become active participants in their learning process (Ranchhod et al., 2014). The experiences and emotions that arise during the process will never be identical for each individual, just as the students' attitudes will vary depending on the scenario simulated. Although students may have sufficient motivation, in the context of business simulation games the large amounts of information generated in short periods of time may overwhelm them (Voss and Brennan, 2010). Therefore, we suggest that students who consider the game as being highly important will be more likely to feel 'overwhelmed' and experience increased levels of anxiety:

$\mathrm{H} 2$ : When playing business simulation games, students experience greater computer anxiety when they perceive that their participation in the game has a high importance level, compared to when the perceived importance of the computer activities is low.

\subsection{Knowledge}

Student anxiety in the use of computers in general, and software in particular, is often reduced when the student feels more selfefficient and has higher levels of knowledge and experience (Havelka, 2003; Havelka et al., 2004). Generally, students with higher levels of computer-related anxiety usually have fewer computer skills (Barbeite and Weiss, 2004; Mac Callum et al., 2014), and tend to perceive the technology as having a greater level of complexity (van Raaij and Schepers, 2008).

However, in the context of business simulation games, in which students handle large amounts of information and the results obtained vary depending on the other players, we do not consider that knowledge per se significantly reduces anxiety levels. Under time constraints when using the software, a great amount of knowledge to be implemented could even mean greater stress. Thus, we expect that in this scenario the perceived importance and locus of control have less impact on computer anxiety as the student's prior knowledge increases.

In this vein, Perry and Morris (2005) found that individuals with an external locus generally have less financial knowledge compared with those with an internal locus, which leads them to have less responsible financial behavior. The authors found that the influence between financial knowledge and behavior in this matter was mediated by the locus of control. In another study, conducted in a totally different context, participants were asked to pedal a stationary bike while their heart rate was monitored (Perez-Garcia et al., 2002). When digital information was provided to individuals on their physical performance, the heart rate was higher in conditions of internal than external locus; furthermore, the external-locus participants often experienced a greater increase in blood pressure when misinformation was given, compared with when no information was given. Thus, the role 
of locus of control on heart rate (one of the medical symptoms of anxiety) was dependent on the presence of information.

In short, and despite the fact that there is a literature gap in this area, the existence of a moderating effect of knowledge on the role of the locus of control over computer anxiety is expected. Thus, we expect that:

H3: The students' knowledge moderates the effect of locus of control on computer anxiety.

In computer games, anxiety arises when the player has the perception that the challenge is much bigger than the player's skills, with the opposite scenario (many skills and low challenge) being the threshold of boredom. Thus, a state of balance between challenge and skills is likely to lead the player to a state of immersion in the activity (Kiili, 2005). Furthermore, computer anxiety will not depend on either the degree of importance or the "challenge' alone, but rather the balance between these aspects and the required knowledge or skills, which could play a moderating role. Therefore,

H4: The students' knowledge moderates the effect of the perceived importance of the computer activities on computer anxiety.

\section{METHOD}

To test our hypotheses, we conducted an experiment with students who were taking a course in which an online business simulation game was used as a learning and evaluation tool. Specifically, the experiment involved a 2 (perceived importance: high vs. low) x 2 (locus of control: internal vs. external) design. The following section provides more detail on the characteristics of the study.

\subsection{Participants}

Participants were 106 fourth-year Business Administration students. Seventy percent of the respondents were women and their average age was 22 years. They participated in a business simulation game named $R A D M K T$, which was hosted online on a web server of the Spanish company Gestionet (http://gestionet. net/en/). Appendix includes some screenshots of the game.

In the digital simulation game, students are organized in teams consisting of five members and each team plays a role as managers of a firm dedicated to the manufacturing and sale of three products (an oil radiator, RAD; a portable air conditioning system, AIR; and a mixed product denominated Multi Split, MSP) in three areas (Spain, European Union and South America). With the aim of maximizing benefits, the manager has to apply differentiated business strategies for each product.

In this digital environment, students have to make decisions related to the areas of production (order of production), human resources (training, hiring, firing, remunerating), financing, R\&D (research and development) and innovation and marketing (prices, distribution, publicity, promotion). They have one and a half hours to accomplish this task.
Prior to every move, the teams are given information about the firm itself and its environment which they have to analyse to make their decisions: (a) Market research: a study on the demand forecast for each product in each market and another on brand image. (b) Information on the environment: inflation and exchange rates, as well as data on the decisions made by both the firm itself and its competitors in previous periods. (c) Accounting information: profit and loss account, balance sheet and unit price of each product (unit manufacturing cost, unit marketing cost and financial and general cost).

Each firm makes decisions to maximize an index that generates a score from 0 to 1000 points based on various descriptors (including the firm's quarterly benefits, financial situation, effects of sales force and advertising, etc.). This score and the business ranking are only shown at the end of the session.

Students are evaluated with a mark as a result of two issues: (a) position in the ranking and (b) performance (management reports, business meetings, written tests and monitoring). Individual tasks account for $40 \%$ of the mark and the team tasks for the $60 \%$.

\subsection{Study design and procedure}

An initial sample of 106 students took part in the experiment, who randomly received one of the four types of questionnaires with the same questions but different information manipulations. After reviewing questionnaires with missing data and outliers, the sample was reduced to 91 individuals. Participants first read a text that described the study and varied according to the experimental conditions. In this study, we used two versions for each of the independent factors: perceived importance (high vs. low) and locus of control (internal vs. external) (Table 1). Specifically, a direct question was employed to measure the degree of importance attached to the game. Then, the locus of control was measured by asking individuals if they felt that the outcome of the game depended on themselves, controlled it and had a sense of power, which indicates psychological empowerment (Patrick and Hagtvedt, 2012). The higher the values on this three-item scale, the higher the internal locus will be.

The respondents were asked to indicate whether some good descriptions apply to his or her mood using 7-point Likert-type scales in most cases. Specifically, the respondents had to indicate their level of computer anxiety via four items level of worry, fear and learning about computers (Barbeite and Weiss, 2004; Cowan and Jack, 2013). The first item was a direct question about their level of anxiety towards the use of the game, while in subsequent items, they were asked to indicate their degree of agreement with the items 'I'm worried about the game', 'I am thinking a lot about how I will fare in the game' and 'I want to know as much as possible about the game'. These items were inspired by the work of Barbeite and Weiss (2004), who distinguished between anxiety using computers and anxiety in computer-related activities. 
Table 1. Text provided to students.

\begin{tabular}{|c|c|}
\hline Version & Text provided to students \\
\hline High importance & $\begin{array}{l}\text { As you know, today you will have the first chance to use the } R A D M K T \text { simulator. This will be critical, as it will enable you } \\
\text { to learn how to use the application and develop business strategies. What you do will have an impact on your final score }\end{array}$ \\
\hline Low importance & $\begin{array}{l}\text { As you know, today you will have the first chance to use the } R A D M K T \text { simulator. This will only be a practice run, and } \\
\text { what you do within the simulator will not have any impact on your final score }\end{array}$ \\
\hline External locus & $\begin{array}{l}\text { We remind you that the success of your company mainly depends on the success or failure of the other players, as well as } \\
\text { the environmental conditions of the simulation. Therefore, the choices you make today may not serve you tomorrow }\end{array}$ \\
\hline Internal locus & $\begin{array}{l}\text { We remind you that the success of your company mainly depends on your own knowledge and skills. The variables that } \\
\text { determine the outcome of the game will directly depend on your decisions as a manager }\end{array}$ \\
\hline
\end{tabular}

Moreover, the questionnaire included questions about variables that could interfere with how the individuals valued each item: the information provided in class on the game's features and the evaluation system, and their business management knowledge. Both scales were measured by 10-point scales.

Satisfaction was measured using three items extracted from Hennig-Thurau's (2004) scale; this entailed satisfaction with the obtained result, the overall experience $(1=$ very unsatisfied, $7=$ very satisfied) and the fulfillment of expectations $(1=$ none at all, $7=$ fully $)$, as well as an additional item concerning satisfaction with their teamwork $(1=$ very unsatisfied, $7=$ very satisfied). We also used a 7-point Likert-type scale to measure the students' general attitude towards the simulator (negative/positive, unfavorable/favorable, bad/good) based on the work of Lafferty and Goldsmith (2005). Finally, the final scores obtained for each virtual company were included.

To test $\mathrm{H} 1$ and $\mathrm{H} 2$, we used an ANOVA model in which the dependent variable was computer anxiety (CAN) and both experimental treatments were the independent variables (Field and Hole, 2003). In order to analyse the moderating effect of the knowledge variable ( $\mathrm{H} 3$ and $\mathrm{H} 4)$, the database was divided according to the mean and standard deviation (SD) of the variable (Group 1: knowledge $\leq$ mean $+0.25 * \mathrm{SD}$; Group 2: knowledge $\geq$ mean $+0.25 * \mathrm{SD}$ ). Once this division had been applied, an independent ANOVA was performed for each subsample. The option of utilizing an ANCOVA model was ruled out as we had not measured the students' knowledge prior to our experimental manipulations.

Finally, a cluster analysis was performed to review the existence of groups of students with experience in the use of simulation games. The variables were satisfaction, locus, importance, knowledge, information, computer anxiety and evaluation (business ranking).

\section{RESULTS}

\subsection{Hypothesis testing}

We conducted an analysis using IBM SPSS 22.0 in order to test the reliability of scales. Cronbach's alpha reliability for all scales was above 0.7 and item-total-correlation was above 0.3 . The mean scores for each scale were calculated and used in subsequent analysis. Descriptive results are shown in Table 2.
Results of the ANOVA and ANCOVA analysis are shown below.

First, it was hypothesized that those with an internal locus of control will report more computer anxiety, and as results show, Hypothesis 1 is confirmed $\left(\mathrm{CAN}_{\mathrm{I}-\mathrm{LOC}}=5.00\right.$ vs. $\mathrm{CAN}_{\mathrm{E}-\mathrm{LOC}}=$ 4.47; $F=7.179 ; P<0.01$ ). Second, Hypothesis 2 proposed that those who perceived more importance of the activities will report more computer anxiety $\left(\mathrm{CAN}_{\mathrm{H}-\mathrm{IMP}}=4.94\right.$ vs. $\mathrm{CAN}_{\mathrm{L}-\mathrm{IMP}}=$ $4.48 ; F=5.851 ; P<0.05)$; hence, Hypothesis 2 is also confirmed.

Hypothesis 3 and 4 predicted a moderating effect of students' knowledge on the effects of computer anxiety. Results show that those with an internal locus of control will report more computer anxiety and this effect will be reinforced with a high level of knowledge $\left(\mathrm{CAN}_{\mathrm{I}-\mathrm{LOC} / \mathrm{H}-\mathrm{KNOW}}=5.44 \mathrm{vs}\right.$. $\left.\mathrm{CAN}_{\mathrm{E}-\mathrm{LOC} / \mathrm{H}-\mathrm{KNOW}}=4.09 ; F=7.533 ; P<0.05\right)$; hence, Hypothesis 3 is confirmed. Finally, those who perceive more importance of the task will report more computer anxiety and this effect will be weakened with a low level of knowledge $\left(\mathrm{CAN}_{\mathrm{H}-\mathrm{IMP} / \mathrm{L}-\mathrm{KNOW}}=4.80 ; \mathrm{CAN}_{\mathrm{L}-\mathrm{IMP} / \mathrm{L}-\mathrm{KNOW}}=4.08 ; F=\right.$ 6.533; $P<0.05$ ); thus, Hypothesis 4 is confirmed. Therefore, students with a high level of knowledge can experience greater levels of computer anxiety if they feel either an internal locus of control or have to deal with important tasks.

Furthermore, the study also tested whether the previous information has a moderating effect. Results suggested that the positive effect of internal locus of control on computer anxiety will be reinforced in those who have a high level of previous information $\left(\mathrm{CAN}_{\mathrm{I}-\mathrm{LOC} / \mathrm{H}-\mathrm{INF}}=5.23\right.$ vs. $\mathrm{CAN}_{\mathrm{E}-\mathrm{LOC} / \mathrm{H}-\mathrm{INF}}=4.39 ; F=$ 5.819; $P<0.05)$. On the contrary, results also suggested that the positive effect of perceived importance on computer anxiety will be higher as information decreases $\left(\mathrm{CAN}_{\mathrm{H}-\mathrm{IMPOR} / \mathrm{L}-\mathrm{INF}}=5.30\right.$ vs. $\left.\mathrm{CAN}_{\mathrm{L}-\mathrm{IMP} / \mathrm{L}-\mathrm{INF}}=4.06 ; F=14.818 ; P<0.01\right)$. Consequently, both previous information and the students' level of knowledge have a similar effect on computer anxiety.

Figures 1 and 2 show the moderating effects of prior knowledge and information.

\subsection{Cluster analysis}

We conducted a two-step cluster analysis of eight factors (satisfaction, ranking, computer anxiety, locus of control, attitude, 
Table 2. Descriptive results of the experiment.

\begin{tabular}{|c|c|c|c|c|c|}
\hline & & \multicolumn{2}{|c|}{$\begin{array}{l}\text { Internal locus } \\
\text { (I-LOC) }\end{array}$} & \multicolumn{2}{|c|}{$\begin{array}{l}\text { External locus } \\
\text { (E-LOC) }\end{array}$} \\
\hline & & Mean & S.D. & Mean & S.D \\
\hline \multirow[t]{4}{*}{ High importance (H-IMP) } & C.Anxiety (CAN) & 5.280 & 0.775 & 4.615 & 0.983 \\
\hline & Satisfaction (SAT) & 5.210 & 1.045 & 5.154 & 1.215 \\
\hline & Attitude (ATT) & 5.653 & 0.796 & 5.308 & 1.028 \\
\hline & Word-of-Mouth (WOM) & 5.740 & 0.723 & 5.365 & 0.782 \\
\hline \multirow[t]{4}{*}{ Low importance (L-IMP) } & C.Anxiety (CAN) & 4.667 & 1.127 & 4.276 & 0.799 \\
\hline & Satisfaction (SAT) & 5.060 & 1.447 & 4.711 & 1.461 \\
\hline & Attitude (ATT) & 5.413 & 1.027 & 5.211 & 1.112 \\
\hline & Word-of-Mouth (WOM) & 5.381 & 0.705 & 5.316 & 0.975 \\
\hline
\end{tabular}

S.D., standard deviation.

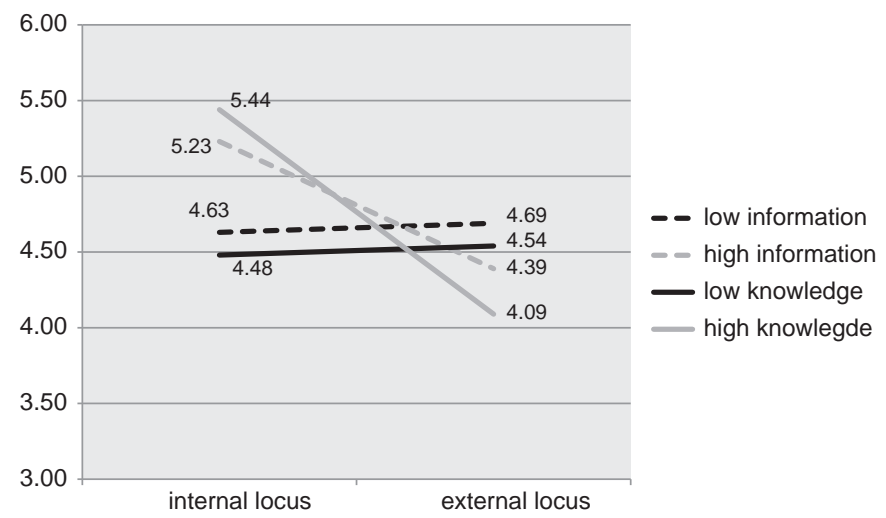

Figure 1. Moderating effects of locus of control on computer anxiety.

perceived importance, knowledge and prior information) using log-likelihood distance measure and Schwarz's Bayesian Criterion (BIC) to determine the number of clusters. Based on the results, three clusters were determined. As shown in Table 3 , the variance on the average frequency of satisfaction and position in the ranking achieve the level of significance and is higher than that of the other variables. Other variables (locus of control, knowledge, prior information, importance perceived and attitude) also achieve the level of significance.

The three clusters account for 35\% (Cluster 1), 20\% (Cluster 2) and $45 \%$ (Cluster 3) of the total students. Approximately, $35 \%$ of the students are centered in Cluster 1 and the average frequency of satisfaction $(\bar{X}=6.8)$, position in the ranking (firstsecond) and attitude $(\overline{\mathrm{X}}=5.88)$ was higher than that of the other two clusters. Approximately, $45 \%$ of the students are centered in Cluster 3 and the average frequency of satisfaction $(\bar{X}=3.9)$, position in the ranking (fourth-fifth) and attitude $(\overline{\mathrm{X}}=5.11)$ was lower than that of the other two clusters. However, the average frequency of prior knowledge was the highest of the three clusters, suggesting that approximately $45 \%$ playing this simulation game exhibit dissatisfaction because the percentage of students in this cluster having prior knowledge (i.e. 72.2\%) was higher

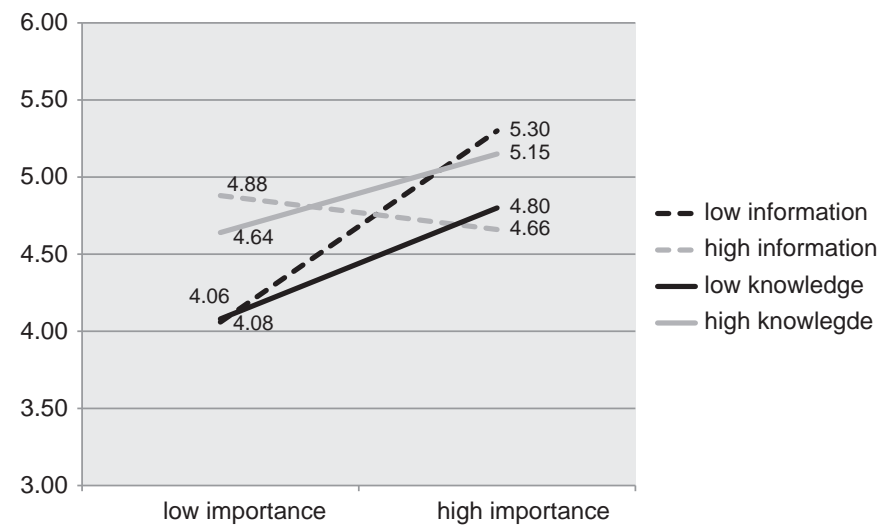

Figure 2. Moderating effects of perceived importance on computer anxiety.

than the other two clusters and exhibit the worst position in the ranking. The analysis also shows that $20 \%$ of the students are centered in Cluster 2, suggesting that $20 \%$ of players report a medium satisfaction level because they exhibit an internal locus of control (i.e. 75\%) and prior information (i.e. 100\%).

\section{DISCUSSION}

The use of a new ICT can generate anxiety in students, driven by their fear of using the computer effectively. The results showed that anxiety due to the use of technology is increased by the existence of an internal locus of control. Thus, though there is currently no academic consensus regarding whether environmental influences are more important than factors that are inherent in the individual, this research suggests that self-motivation is the most important element for a student to achieve their goals. In this case, students perceive that they can modify their behavior and attitudes to succeed, which serves as great motivation to change their behavior where needed; this opens a line of possibilities to decrease anxiety in the use of new ICTs. 
Table 3. Cluster analysis.

\begin{tabular}{lcllll} 
& $\begin{array}{l}\text { Feature } \\
\text { importance }\end{array}$ & Cluster 1 (35\%) & Cluster 2 (20\%) & Cluster 3 (45\%) & $\mathrm{F} / \chi^{2}$ \\
Satisfaction & 1.00 & 6.18 & 5.5 & 3.9 & $50.006^{* * *}$ \\
Ranking & 0.90 & $1^{\circ} / 2^{\circ}(100 \%)$ & $3^{\circ}(62.5 \%)$ & $4^{\circ} / 5^{\circ}(88.9 \%)$ & $50.271^{* * *}$ \\
Knowledge & 0.35 & Little knowledge $(100 \%)$ & Little knowledge (50\%) & Many knowledge (72.2\%) & $17.039^{* * *}$ \\
Information & 0.19 & Uninformed (57.1\%) & Very informed (100\%) & Uninformed (61.1\%) & $9.097^{* *}$ \\
Locus of control & 0.17 & External locus (85.7\%) & Internal locus (75\%) & External locus (61.1\%) & $8.034^{* *}$ \\
Importance & 0.16 & Low importance (57.1\%) & High importance (100\%) & High importance (50\%) & $7.556^{* *}$ \\
Attitude & 0.14 & 5.88 & 5.42 & 5.11 & $3.591^{* *}$ \\
C.Anxiety & 0.01 & 4.43 & 4.78 & 4.62 & 0.278 \\
\hline
\end{tabular}

${ }^{* * *} P<0.001,{ }^{* *} P<0.05$.

Furthermore, the results suggest that computer anxiety decreases if the user perceives the task at hand to be of less importance.

In summary, the question is how can students be motivated to feel relaxed in class when playing online games, and not experience high levels of anxiety? There are several answers to this, which enable perceived threats to be minimized. First, it is necessary for students to control the technology used, so teachers should facilitate use of the ICT. Second, it is necessary for the students to feel safe in using the technology, controlling it, and including their personal information. Third, teachers must be able to answer all questions from students about use of new technology, for which teachers must be trained. And last, but not least, the success of this learning tool requires an innovative climate, which can only be developed with teachers who are engaged with innovation in education.

\subsection{General implications}

An important aspect of decreasing anxiety in computing classes pertains to the teacher, who plays an important role in how the students feel and how they use computers as learning tools. A positive attitude from teachers is essential to reduce students' fear when using computers in the classroom. When a teacher uses a simulation game in class, bidirectional communication with students will improve students' self-confidence and likelihood of success in the game. Communication allows students to explain their beliefs and fears, and also to improve their knowledge of the new technology and their perceived control over it. Self-efficacy will give rise to students' favorable feelings regarding the experience of using computers, which must be promoted by the teacher and coupled with a relationship based on mutual trust.

Therefore, the teacher plays a key role in cultivating students' positive attitudes and engagement with technology. Besides attitude, another key to obtaining a positive experience from the use of management simulators relates to the game score. In this respect, the teacher is responsible for motivating student teams to achieve the highest score possible, while keeping students with the worst scores from wanting to withdraw from the game.
This learning tool allows students to easily obtain coursespecific skills. In the case of business environments, one of the main skill areas is team working, such as leadership and negotiation skills. Other skills include data analysis, operating to deadlines, and exercising autonomy in making decisions.

The results of this research are generalizable to other subjects and degrees in which similar skills are needed, such as medicine. In medicine degrees, teachers usually employ medical simulators to train prospective doctors. Students are required to make decisions about a range of medical issues after analysing data, while collaborating with their team mates.

\subsection{Implications on the design of games for education}

According to results, students perceive a lower computer anxiety if the tasks seem to be of less importance. This leads us to propose that users could enter online games using a guest password, so that they will perceive there to be lower risk associated with other users' viewing their private information (Osatuyi, 2015). These results are tempered by the previous knowledge that students have, and the relevant information at their disposal. Thus, before beginning to use online business simulation games, teachers should learn as much about the games as possible, in order to help them answer the students' questions with ease (Voss and Brennan, 2010).

Given that an internal locus of control is associated with computer anxiety, simulation games should increase the number of variables whose result has a random component (financial investments, $R \& D$ productivity, etc.). In this way, students will experience less internal pressure and their expectations of winning will decrease, which are closely related to satisfaction.

Games for educational purposes should also include a module for acquiring basic knowledge of the games' contents. This will allow teachers to standardize the students' level of knowledge and 'neutralize' its potential effects on anxiety and satisfaction.

One final suggestion is that simulation games could include a set of learning indicators (e.g. financial knowledge, data analysis) to assess the acquisition of skills, rather than virtual company performance. The course assessment could also be 
linked to these learning indicators, rather than depending on the final ranking.

\subsection{Future studies}

Future work should investigate whether these results are maintained through the use of different teaching technologies; for example, mobile apps. In addition, instead of considering computer anxiety arising from use, other contexts could be studied, such as users' frustration from being unable to use their mobile devices, and thus the psychological dependence that these devices create. In fact, it has been demonstrated that such frustration is greater when there is an overuse, and the longer the person must go without being able to use the device (Cheever et al., 2014).

In this paper, teams were relatively homogeneous in terms of gender ( $70 \%$ women) and age (22 years on average), which could have skewed the results obtained to some extent. Further research could thus focus on other sociodemographic profiles, in addition to analysing variables related to team performance (team cohesiveness, leadership roles, etc.). Finally, potential studies can investigate how computer anxiety can impact student satisfaction in cases where the assessment system is different and competitiveness is not a factor, as is often the case in subjects in which business simulation games are used.

\subsection{Main conclusions}

This paper focused on the use of online simulation games. Specifically, we analysed how students can exhibit less computer anxiety and defined clusters of users to explain the most important variables regarding satisfaction with their use of a business simulation game.

Our findings show that students perceive higher anxiety when they perceive a high internal locus of control and that when they perceive that their participation in the game is highly important. These effects are moderated by the students' knowledge and previous information given by the instructor. However, satisfaction is mainly affected by their final score on the business game rather than on individual traits.

The results also suggest the existence of clusters of users in online simulation games. The main conclusion here is that anxiety becomes unimportant when explaining satisfaction arising from playing the online simulation game. This is because the most important factor that explains satisfaction with use of the technology is the final score obtained for the virtual company. Thus, the final score is the variable with the greatest weight, which is in line with previous evidence suggesting that the user satisfaction is closely related to the profits made by the virtual company (Ben-Zvi, 2010). This is because the students are practicing real-time management, which closely reflects the real business world. Thus, business simulation games are a didactic tool that allows students to participate in a realistic experience.

\section{SUPPLEMENTARY MATERIAL}

Supplementary data is available at Interacting with Computers online.

\section{FUNDING}

The authors express their gratitude for financial support received from the Spanish Government (ECO2014-54760, ECO2013-41257-P and ECO2017-83993-P) and from the Regional Government and European Social Funding (Fondo Social Europeo) (Generés S09).

\section{REFERENCES}

Amyx, D., Mowen, J. C. and Hamm, R. (2000) Who really wants health-care choice? J. Manag. Med., 14, 272-290. doi:10.1108/ 02689230010362891.

Barbeite, F. G. and Weiss, E. M. (2004) Computer self-efficacy and anxiety scales for an Internet sample: testing measurement equivalence of existing measures and development of new scales. Comput. Hum. Behav., 20, 1-15. doi:10.1016/S0747-5632(03)00049-9.

Beckers, J. J., Wicherts, J. M. and Schmidt, H. G. (2007) Computer anxiety: 'trait' or 'state'? Comput. Hum. Behav., 23, 2851-2862. doi:10.1016/j.chb.2006.06.001.

Ben-Zvi, T. (2010) The efficacy of business simulation games in creating Decision Support Systems: an experimental investigation. Decision Support Syst., 49, 61-69. doi:10.1016/j.dss.2010.01.002.

Boker, A., Brownell, L. and Donen, N. (2002) The Amsterdam preoperative anxiety and information scale provides a simple and reliable measure of preoperative anxiety. Can. J. Anesth., 49, 792-798. doi:10.1007/BF03017410.

Bozionelos, N. (2001) Computer anxiety: Relationship with computer experience and prevalence. Comput. Hum. Behav., 17, 213-224. doi:10.1016/S0747-5632(00)00039-X.

Burroughs, J. E. and Mick, D. G. (2004) Exploring antecedents and consequences of consumer creativity in a problem-solving context. J. Consum. Res., 31, 402-411. doi:10.1086/422118.

Cheever, N. A., Rosen, L. D., Carrier, L. M. and Chavez, A. (2014) Out of sight is not out of mind: The impact of restricting wireless mobile device use on anxiety levels among low, moderate and high users. Comput. Hum. Behav., 37, 290-297. 10.1016/j.chb. 2015.02.062.

Cleveland, M., Kalamas, M. and Laroche, M. (2005) Shades of green: linking environmental locus of control and proenvironmental behaviors. J. Consum. Market., 22, 198-212. doi:10.1108/07363760510605317.

Cools, E. and van den Broeck, H. (2008) The hunt for the Heffalump continues: can trait and cognitive characteristics predict entrepreneurial orientation? J. Small Business Strat., 18, 23-41.

Cowan, B. R. and Jack, M. A. (2014) Measuring anxiety towards Wiki editing: investigating the dimensionality of the Wiki anxiety 
inventory-editing. Interact. Comput., 26, 557-571. doi:10.1093/ iwc/iwt050.

Field, A. and Hole, G. (2003) How to Design and Report Experiments. SAGE Publications, London.

Größler, A. (2004) Don't let history repeat itself-methodological issues concerning the use of simulators in teaching and experimentation. Syst. Dynam. Rev., 20, 263-274. doi:10.1002/sdr.286.

Hair, M., Renaud, K. V. and Ramsay, J. (2007) The influence of selfesteem and locus of control on perceived email-related stress. Comput. Hum. Behav., 23, 2791-2803. doi:10.1016/j.chb.2006.05.005.

Havelka, D. (2003) Predicting software self-efficacy among business students: a preliminary assessment. J. Inform. Syst. Educ., 14, 145-152.

Havelka, D., Beasley, F. and Travis, B. (2004) A study of computer anxiety among business students. Mid-Am. J. Business, 19, 1-9. doi: $10.1108 / 19355181200400007$.

Heider, F. (1958) The Psychology of Interpersonal Relations. Wiley, New York.

Hennig-Thurau, T. (2004) Customer orientation of service employees. Int. J. Service Ind. Manag., 15, 460-478. doi:10.1108/ 09564230410564939.

Hsu, M. K., Wang, S. W. and Chiu, K. K. (2009) Computer attitude, statistics anxiety and self-efficacy on statistical software adoption behavior: an empirical study of online MBA learners. Comput. Hum. Behav., 25, 412-420. doi:10.1016/j.chb.2008.10.003.

Huang, W-H. D., Hood, D. W. and Yoo, S. J. (2013) Gender divide and acceptance of collaborative Web 2.0 applications for learning in higher education. Internet Higher Educ., 16, 57-65. doi:10. 1016/j.iheduc.2012.02.001.

Joo, Y. J., Joung, S. and Sim, W. J. (2011) Structural relationships among internal locus of control, institutional support, flow, and learner persistence in cyber universities. Comput. Hum. Behav., 27, 714-722. doi:10.1016/j.chb.2010.09.007.

Kiili, K. (2005) Content creation challenges and flow experience in educational games: the IT-Emperor case. Internet Higher Educ., 8, 183-198. doi:10.1016/j.iheduc.2005.06.001.

Kim, H. K. and Davis, K. E. (2009) Toward a comprehensive theory of problematic Internet use: evaluating the role of self-esteem, anxiety, flow, and the self-rated importance of Internet activities. Comput. Hum. Behav., 25, 490-500. doi:10.1016/j.chb.2008.11.001.

Koo, D. M. (2009) The moderating role of locus of control on the links between experiential motives and intention to play online games. Comput. Hum. Behav., 25, 466-474. doi:10.1016/j.chb. 2008.10.010.

Lafferty, B. A. and Goldsmith, R. E. (2005) Cause-brand alliances: does the cause help the brand or does the brand help the cause? J. Business Res., 58, 423-429. doi:10.1016/j.jbusres.2003.07.001.

Liaw, S-S. and Huang, H-M. (2013) Perceived satisfaction, perceived usefulness and interactive learning environments as predictors to self-regulation in e-learning environments. Comput. Educ., 60, 14-24. doi:10.1016/j.compedu.2012.07.015.

Mac Callum, K., Jeffrey, L. and Kinshuk (2014) Comparing the role of ICT literacy and anxiety in the adoption of mobile learning. Comput. Hum. Behav., 39, 8-19. doi:10.1016/j.chb.2014.05.024.
Martin, A. (2000) The design and evolution of a simulation/game for teaching information systems development. Simul. Gaming Interdiscip. J., 31, 445-463. doi:10.1177/104687810003100401.

Osatuyi, B. (2015) Is lurking an anxiety-masking strategy on social media sites? The effects of lurking and computer anxiety on explaining information privacy concern on social media platforms. Comput. Hum. Behav., 49, 324-332. doi:10.1016/j.chb. 2015.02.062.

Parayitam, S., Desai, K. J., Desai, M. S. and Eason, M. K. (2010) Computer attitude as a moderator in the relationship between computer anxiety, satisfaction, and stress. Comput. Hum. Behav., 26, 345-352. doi:10.1016/j.chb.2009.11.005.

Patrick, V. M. and Hagtvedt, H. (2012) I don't' versus 'I can't': when empowered refusal motivates goal-directed behavior. J. Consumer Res., 39, 371-381. doi:10.1086/663212.

Perez-Garcia, A. M., Sanjuan, P. and Bermudez, J. (2002) Control personal y situacional y reactividad cardiovascular en tareas de estrés físico. Psicothema, 14, 583-590.

Perry, V. G. and Morris, M. D. (2005) Who is in control? The role of self-perception, knowledge, and income in explaining consumer financial behavior. J. Consumer Affairs, 39, 299-313. doi:10.1111/j.1745-6606.2005.00016.x.

Rahimi, M. and Yadollahi, S. (2011) Computer anxiety and ICT integration in English classes among Iranian EFL teachers. Proc. Comput. Sci., 3, 203-209. doi:10.1016/j.procs.2010.12.034.

Ranchhod, A., Gurau, C., Loukis, E. and Trivedi, R. (2014) Evaluating the educational effectiveness of simulation games: a value generation model. Inform. Sci., 264, 75-90. doi:10.1016/j. ins.2013.09.008.

Rotter, J. B. (1966) Generalized expectancies for internal and external control of reinforcement. Psychol. Monogr. General Appl., $80,1-28$.

Saadé, R. G. and Kira, D. (2007) Mediating the impact of technology usage on perceived ease of use by anxiety. Comput. Educ., 49, 1189-1204. doi:10.1016/j.compedu.2006.01.009.

Siewiorek, A., Saarinen, E., Lainema, T. and Lehtinen, E. (2012) Learning leadership skills in a simulated business environment. Comput. Educ., 58, 121-135. doi:10.1016/j.compedu.2011.08.016.

Smith, B. and Caputi, P. (2007) Cognitive interference model of computer anxiety: implications for computer-based assessment. Comput. Hum. Behav., 23, 1481-1498. doi:10.1016/j.chb.2005.07.001.

Sun, P. C., Tsai, R. J., Finger, G., Chen, Y. Y. and Yeh, D. (2008) What drives a successful e-learning? An empirical investigation of the critical factors influencing learner satisfaction. Comput. Educ., 50, 1183-1202. doi:10.1016/j.compedu.2006.11.007.

Tao, Y., Cheng, C. H. and Sun, S. (2012) Alignment of teaching and student perceptions on the continued use of business simulation games. Educ. Technol. Soc., 15, 177-189.

van Raaij, E. M. and Schepers, J. J. (2008) The acceptance and use of a virtual learning environment in China. Comput. Educ., 50, 838-852. doi:10.1016/j.compedu.2006.09.001.

Vitasari, P., Wahab, M. N. A., Othman, A. and Awang, M. G. (2010) A research for identifying study anxiety sources among 
university students. Int. Educ. Stud., 3, 189-196. doi:10.5539/ ies.v3n2p189.

Voss, L. and Brennan, R. (2010) Marketing simulation games: student and lecturer perspectives. Market. Intell. Plan., 28, 882-897. doi:10.1108/02634501011086472.
Wallston, K. A., Wallston, R. S. and DeVellis, R. (1978) Development of the multidimensional health locus of control (MHLC) scales. Health Educ. Monogr., 6, 160-70.

Walters, B. A. and Coalter, T. M. (1997) Simulation games in business policy courses: is there value for students? J. Educ. Business, 72, 170-174. doi:10.1080/08832323.1997.10116849. 